\title{
Social Isolation and Mortality Among People Living with HIV in British Columbia, Canada
}

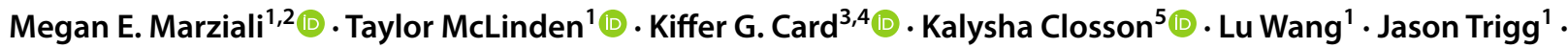 \\ Kate Salters ${ }^{1,4} \cdot$ Viviane D. Lima ${ }^{1,6} \cdot$ Surita Parashar ${ }^{1,4} \cdot$ Robert S. Hogg $^{1,4}$
}

Published online: 14 August 2020

(c) Springer Science+Business Media, LLC, part of Springer Nature 2020

\begin{abstract}
Social isolation, a risk factor for poor health within the general population, may be exacerbated by unique challenges faced by people living with HIV (PLHIV). This analysis examines the association between social isolation and all-cause mortality among a cohort of PLHIV experiencing multiple social vulnerabilities. The analytical sample included 936 PLHIV $\geq 19$ years, living in British Columbia, Canada, and enrolled in the Longitudinal Investigation into Supportive and Ancillary Health Services (LISA) Study (2007-2010). Participants were classified as Socially Connected (SC), Minimally Isolated (MI) or Socially Isolated (SI) via latent class analysis. Cross-sectional survey data was linked to longitudinal clinical data from a provincial HIV treatment database. Mortality was assessed longitudinally up to and including December 31st, 2017. Through multivariable logistic regression, an association between SI and all-cause mortality was found (adjusted OR: 1.48; 95\% CI $1.08,2.01)$. These findings emphasize the need to mitigate effects of social isolation among PLHIV.
\end{abstract}

Keywords Social isolation $\cdot$ Social environment $\cdot$ Mortality $\cdot$ HIV $\cdot$ Canada

Electronic supplementary material The online version of this article (https://doi.org/10.1007/s10461-020-03000-2) contains supplementary material, which is available to authorized users.

Robert S. Hogg

bobhogg@cfenet.ubc.ca

1 Epidemiology and Population Health Program, BC Centre for Excellence in HIV/AIDS, 608-1081 Burrard Street, Vancouver, BC V6Z 1Y6, Canada

2 Mailman School of Public Health, Columbia University, New York City, NY, USA

3 Faculty of Human and Social Development, School of Public Health and Social Policy, University of Victoria, Victoria, Canada

4 Faculty of Health Sciences, Simon Fraser University, Burnaby, Canada

5 Faculty of Medicine, School of Population and Public Health, University of British Columbia, Vancouver, Canada

6 Division of Infectious Diseases, Department of Medicine, Faculty of Medicine, University of British Columbia, Vancouver, Canada

\section{Introduction}

Social isolation, a psychosocial determinant of health, refers to objective measurable characteristics resulting in social disconnectedness: a lack of engagement with peers and the larger community $[1,2]$. This construct is distinct from that of loneliness, which refers to subjective feelings of isolation, suggesting that loneliness and social isolation do not necessarily co-occur and should be assessed independently [3-5]. The prevalence of social isolation is increasing in contemporary society and carries with it a potentially underestimated impact on human health [6]. Research suggests that social isolation may contribute to comparable morbidity risks to that of well-established risk factors such as smoking and high blood pressure [7-10]; adverse consequences of isolation include: lower self-rated physical health [2], poor mental health outcomes [11, 12], chronic inflammation $[1,7,13$, 14], cardiovascular disease and events [11, 14-16] and an increase in likelihood of mortality [5, 8, 10-12, 15, 17, 18]. However, to our knowledge, the association between social isolation and all-cause mortality has not yet been explored specifically among people living with HIV (PLHIV).

While there is abundant evidence to show the negative health impacts of stigma and trauma among PLHIV [19], 
the concept of social isolation has yet to be explored. Social isolation among PLHIV may be exacerbated by challenges, such as: heightened risk of frailty that may hinder participation in social activities [20, 21]; experienced or perceived stigma and discrimination that prevent the establishment of social network ties [22-24]; and the loss of integral social network members in the earlier years of the epidemic [25]. These factors are uniquely detrimental and limiting to social relationships among PLHIV, making this population particularly relevant for assessing social isolation.

Further, PLHIV represent a distinct community for whom public health services and interventions have been focused. Therefore, the generation of evidence, in relation to a potential association between social isolation and mortality, would allow healthcare providers and community-based organizations to model interventions appropriately, and provide greater support for PLHIV. Therefore, this study aims to: (1) characterize the degree of isolation experienced within a sample of PLHIV using latent class analysis, and (2) investigate the association between social isolation and all-cause mortality.

\section{Methods}

\section{Participants and Recruitment}

Individuals eligible for enrolment in the Longitudinal Investigation into Supportive and Ancillary Health Services (LISA) Study were $\geq 19$ years of age, had ever initiated antiretroviral therapy (ART) and were residents of British Columbia (BC), Canada. Recruitment was conducted between July 2007 and January 2010 using convenience sampling strategies (e.g., word of mouth, flyers posted at community-based organizations, and letters distributed by HIV physicians) until a sample size of 1000 individuals was reached [26].

Participants' clinical and mortality information, including cause of death, was collected longitudinally through a linkage to the BC Centre for Excellence in HIV/AIDS Drug Treatment Program (DTP). The DTP oversees the distribution of all ART in BC, Canada. Through this program, PLHIV in BC can access ART free of cost, without co-payments; this program is described in detail elsewhere [27-29]. Assessing measures related to social isolation at one time point and mortality longitudinally has been carried out in previous studies [30, 31].

Eligible participants provided written informed consent. Ethical approval for this study was obtained from research ethics boards at the University of British Columbia/Providence Health Care, Simon Fraser University, the University of Victoria and Vancouver Coastal Health (H16-00497).

\section{Social Isolation Measure}

Latent class analysis (LCA) is a cluster detection technique used for identifying latent or hidden and unobserved traits based on proximal characteristics which are then used as a method of grouping individuals $[32,33]$. We employed LCA to measure social isolation among a sample of PLHIV; this methodological approach was used in order to capture the multidimensionality of this construct. Five indicators of social isolation were analyzed to capture the degree of isolation experienced by respondents: How many people live in the same place with you?; Are you in a relationship?; Who do you count on for support and friendship?; Who is the most reliable to count on for support and friendship?; and I've been satisfied with how socially active I am [34]. Furthermore, PLHIV marginalized by socio-structural inequities were oversampled in this study, resulting in many participants reporting that they were currently experiencing homelessness. Due to previous research outlining the nature of homelessness as an isolating experience [35, 36], these participants were classified as living alone.

\section{All-Cause Mortality Measure}

Mortality was assessed longitudinally, up to and including December 31st, 2017. These data were accessed through the aforementioned data linkage with the DTP, which includes time-updated mortality information collected from the BC Vital Statistics Agency. Through the use of ICD-10 codes, cause of death was categorized as: accident or suicide; chronic disease or co-morbidities including non-AIDSrelated cancers, cardiovascular disease, pulmonary disease, kidney failure/disease, and liver disease (such as Hepatitis C, cirrhosis); drug and/or alcohol related; HIV-related (e.g. other infections related to HIV) and AIDS-defining cancers; and unknown (Table IS). While focusing on all-cause mortality (death from any cause) in the regression models, we also provide descriptive statistics regarding specific causes of death.

To further describe mortality within this sample of PLHIV, an age-standardized all-cause mortality rate (per 1000-person years [PYs]) for both the overall sample and each social isolation class, was estimated using the 2016 Canadian standard population as reference [37].

\section{Confounder Measures}

Potential confounders were selected a priori based on their hypothesized association with social isolation and allcause mortality $[9,18]$. Sociodemographic confounders included: age (continuous), gender (man vs. woman), sexual 
orientation (straight, gay and lesbian, bisexual and other), ethnicity (White, Indigenous, and other), stable housing (yes vs. no), Regional Health Authority at time of interview (Interior Health, Fraser Health, Vancouver Coastal Health, Island Health, Northern Health), and perceived neighbourhood cohesion, a measure assessing an individual's sense of belonging in a neighbourhood (range: $0-100$; higher scores indicate a greater sense of neighbourhood belongingness) [38]. Regional health authorities exist as a means of governing and delivering health-care within specific geographical areas within BC [39].

Socioeconomic confounders included education (some high school or less vs. $\geq$ high school) and reporting current employment (yes vs. no).

Behavioral confounders encompassed history of incarceration (yes vs. no), current illicit drug use (yes vs. no), history of injection drug use (IDU) (yes vs. no), and degree of alcohol use via the CAGE scale, which uses four questions to evaluate whether a participant engages in excessive drinking (range: 0-4; score of $\geq 2$ coded as excessive drinking) [40]. In addition, HIV acceptance was assessed using a 5-response Likert scale for the statement: "I have been able to accept the fact that I have HIV" (strongly agree, agree, neutral, disagree, strongly disagree). Recent violence, including physical, verbal and sexual forms of violence, within 6 months prior to interview (yes vs. no), was included as well.

Clinical confounders included mental health conditions such as: a self-reported diagnosis of a mental health disorder ever (yes vs. no) and depressive symptoms measured through the 10-item validated Center for Epidemiologic Studies Depression (CES-D 10) scale (range: 0-30; cutoff of $\geq 10$ indicating depressive symptoms) [41]. Physical health status was taken into account through adjustment for: body mass index (BMI) [underweight $\left(<18.5 \mathrm{~kg} / \mathrm{m}^{2}\right)$, normal $\left(18.5-24.9 \mathrm{~kg} / \mathrm{m}^{2}\right)$, overweight $\left(25-29.9 \mathrm{~kg} / \mathrm{m}^{2}\right)$, obese $\left(\geq 30 \mathrm{~kg} / \mathrm{m}^{2}\right)$ ] [42], CD4 cell count at time of interview (continuous), and ART adherence ( $\geq 95 \%$ vs. $<95 \%$; 1 year after first ART dispensation date) assessed using a validated method for determining adherence through pharmacy refill data [43].

\section{Statistical Analysis}

LCA was used to group participants based on their experiences of social isolation; this was done using the SAS 9.4 implementation PROC LCA (SAS Institute Inc., NC, USA). Models including two to five latent classes were fit to the sample and a solution was selected using goodness-of-fit criterion. For the fit statistics considered (Akaike information criterion [AIC], Bayesian information criterion [BIC], consistent Akaike information criterion [cAIC], and adjusted Bayesian information criterion [aBIC]), the lowest value represented a better fit [44]. A three-class solution was selected based on best-fit statistical considerations [34].

Further, we employed inverse probability of participation weighting (IPPW) to address potential bias introduced through selective participation, as individuals marginalized by socio-structural inequities were oversampled [45]. As the LISA cohort was originally intended to be representative of the DTP, a population-based sample of all known PLHIV on ART in BC, a hypothetical sample of 'non-respondents' was constructed using sample characteristics from this database. Specifically, given that women, persons of Indigenous ancestry, and people who use injection drugs (PWID) were overrepresented in LISA, the following variables were used as predictors of participation when estimating the weights: sex, ethnicity, and IDU. Each individual was then assigned a weight that reflected the inverse of their probability of participation.

A multivariable logistic regression model, weighted using the IPPW, was used to examine the association between social isolation classes and all-cause mortality, adjusting for sociodemographic, socioeconomic, behavioral, and clinical confounders. Figure 1 outlines the participant inclusion chart, depicting the stages at which participants were excluded from the analysis and the final number of respondents included in the model. Potential confounders were selected for inclusion in the final model through a backward stepwise selection approach, which utilized the relative change in coefficients for social isolation classes as a criterion, until the minimum change from the full model exceeded 5\% [46]. Additional sensitivity analyses were conducted to further explore the relationship between social isolation and all-cause mortality.

\section{Results}

\section{Descriptive Statistics}

Of the 1000 participants in the LISA Study, four were excluded due to missing information necessary for the IPPW; the remaining participants were included in the LCA modelling $(\mathrm{N}=996)$. For the purposes of this analysis, we excluded participants who were lost to follow-up $(\mathrm{N}=60)$ (meaning that mortality information was not available due to respondents having left the province), resulting in an analytical sample of 936 . This sample was composed of 682 (72.9\%) men with a median age of 45 (Quartile 1-Quartile 3 [Q1-Q3]: 40-51). The majority of participants self-identified as straight $(61.8 \%, \mathrm{~N}=578), 65.2 \%(\mathrm{~N}=610)$ identified as White, and 214 (22.9\%) were reportedly employed at time of interview. Weighted percentages and further details regarding descriptive statistics are outlined in Table 1. 
Fig. 1 Participant inclusion chart, depicting the stages at which participants were excluded from analysis

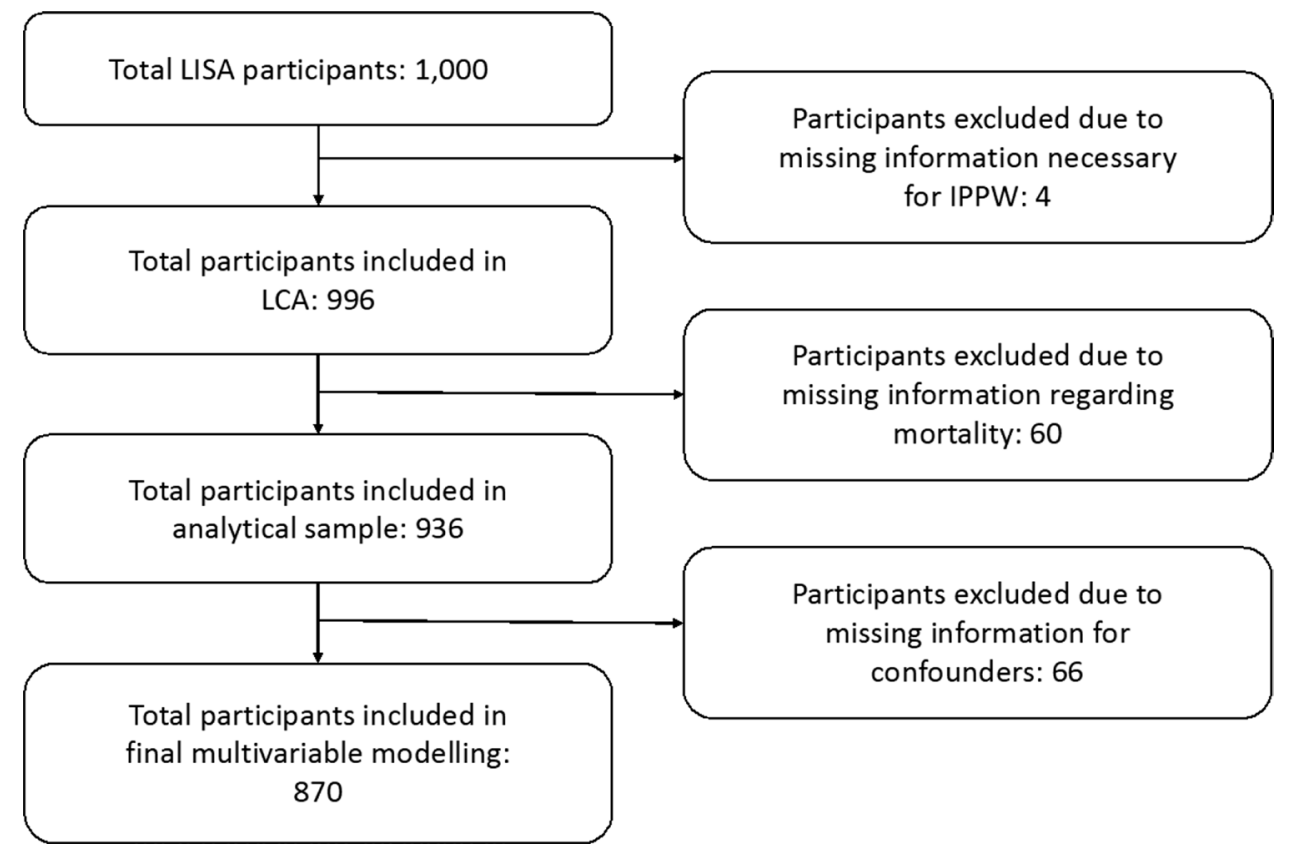

\section{Latent Class Analysis}

Through the use of LCA, three classes of social isolation were identified from the overall sample of 996 respondents. The Socially Connected (SC) class comprised 36.3\% $(\mathrm{N}=340)$ of our sample. Individuals in this class were likely to be living with at least one other person, be in a relationship, have someone to count on for support and friendship, identify someone reliable to count on for support and friendship, and report being satisfied socially.

The largest group, the Minimally Isolated (MI) class, comprised 54.3\% $(\mathrm{N}=508)$ of the sample. Individuals in this group were likely to live alone, were not engaged in any type of relationship, and did not report social satisfaction. However, participants in this class were likely to report having someone reliable to count on for support and friendship.

The Socially Isolated (SI) class comprised 9.4\% ( $\mathrm{N}=88)$ of the sample. Participants classified in this group were likely to live alone, not be engaged in any type of relationship, not be socially satisfied, and lacked the presence of an individual who could act in a supportive role and provide friendship.

\section{Mortality}

Between enrolment (2007-2010) and December 31st, 2017, 229 (24.5\%) participants died during follow-up (Table 2). As outlined in Table 2, the leading cause of death overall was due to chronic disease or co-morbidities $(41.0 \%, \mathrm{~N}=94)$. The second leading cause of death, drug and/or alcoholrelated harms, affected $76(33.2 \%)$ of the participants in our sample. Within each social isolation class, the primary cause of death was consistently chronic disease or co-morbidities (SC: $42.6 \%, \mathrm{~N}=29$; MI: 38.2\%, $\mathrm{N}=52$; SI: $52.0 \%, \mathrm{~N}=13$ ). Similar to the overall breakdown, the second leading cause of death within each isolation class was alcohol and/or drugrelated harms (SC: $29.4 \%, \mathrm{~N}=20$; $\mathrm{MI}: 36.0 \%, \mathrm{~N}=49$; SI: $28.0 \%, \mathrm{~N}=7$ ). Chi-squared analyses revealed that there were no significant differences between latent isolation classes and causes of death (Table 3 ).

The crude all-cause mortality rate for this cohort was 29.2 per 1000 PYs (95\% Confidence Interval [95\% CI] 25.6, 33.2), and the age-standardized all-cause rate was 30.3 per 1000 PYs (95\% CI 22.2, 38.3). Mortality rates were further analyzed by social isolation class, resulting in age-standardized all-cause rates of: 25.9 per 1000 PYs (95\% CI 11.9, 40.0) for the SC class; 31.9 per 1000 PYs (95\% CI 21.4, 42.4) for the MI class; and, 46.6 per 1000 PYs (95\% CI 17.4, 75.9) for the SI class. The rate ratio for the MI class, with the $\mathrm{SC}$ class as a referent, was $1.2(95 \% \mathrm{CI} 0.7,2.3)$; for the SI class, the rate ratio was $1.8(95 \% \mathrm{CI} 0.7,4.5)$.

\section{Multivariable Regression Model}

Potential sociodemographic, socioeconomic, behavioral and clinical confounding factors, as outlined in detail in Table 4, were adjusted for in the multivariable regression model. Participants' missing information for confounders were excluded from the model, resulting in a sample of 870 respondents. Using the SC class as a referent, we quantified a significant association between the SI class and all-cause mortality (Adjusted Odd Ratio [aOR]: 1.48; $95 \%$ CI 1.08, 2.01). Though the MI class was not found 
Table 1 Crude and weighted sample characteristics of participants $(\mathrm{N}=936)$ in the LISA study, comprised of PLHIV living in British Columbia, Canada (2007-2010)

\begin{tabular}{|c|c|c|c|c|}
\hline Variable & $\mathrm{N}=936$ & Crude $\%$ & Weighted $\%$ & $\begin{array}{l}95 \% \text { CI of } \\
\text { weighted } \\
\%\end{array}$ \\
\hline \multicolumn{5}{|l|}{ Exposure } \\
\hline \multicolumn{5}{|l|}{ Social isolation } \\
\hline Socially connected & 340 & 36.3 & 41.8 & $37.8,45.8$ \\
\hline Minimally isolated & 508 & 54.3 & 49.5 & $45.5,53.5$ \\
\hline Socially isolated & 88 & 9.4 & 8.7 & $6.5,10.9$ \\
\hline \multicolumn{5}{|l|}{ Outcome } \\
\hline \multicolumn{5}{|l|}{ Death } \\
\hline No & 707 & 75.5 & 81.8 & $79.0,84.6$ \\
\hline Yes & 229 & 24.5 & 18.2 & $15.4,21.0$ \\
\hline \multicolumn{5}{|l|}{ Sociodemographic confounders } \\
\hline \multicolumn{5}{|l|}{ Gender } \\
\hline Man & 682 & 72.9 & 81.9 & $79.3,84.6$ \\
\hline Women & 254 & 27.1 & 18.1 & $15.4,20.7$ \\
\hline Age (per 1-unit increase) median (Q1-Q3) & 936 & $45(40-51)$ & $46(41-53)$ & - \\
\hline \multicolumn{5}{|l|}{ Sexual orientation } \\
\hline Straight & 578 & 61.8 & 44.3 & $40.4,48.1$ \\
\hline Gay/lesbian & 264 & 28.2 & 47.1 & $43.0,51.2$ \\
\hline Bisexual/other & 94 & 10.0 & 8.6 & $6.5,10.8$ \\
\hline \multicolumn{5}{|l|}{ Ethnicity } \\
\hline White & 610 & 65.2 & 74.6 & $71.4,77.8$ \\
\hline Indigenous & 261 & 27.9 & 15.2 & $13.1,17.4$ \\
\hline Other $^{\mathrm{a}}$ & 65 & 6.9 & 10.2 & $7.5,12.9$ \\
\hline \multicolumn{5}{|l|}{ Stable housing } \\
\hline No & 305 & 32.6 & 19.6 & $17.0,22.1$ \\
\hline Yes & 630 & 67.4 & 80.4 & $77.9,83.0$ \\
\hline Unknown & 1 & - & - & - \\
\hline \multicolumn{5}{|l|}{ Regional health authority } \\
\hline Interior health & 33 & 3.6 & 4.7 & $2.9,6.6$ \\
\hline Fraser health & 175 & 19.1 & 21.9 & $18.4,25.4$ \\
\hline Vancouver coastal health & 609 & 66.5 & 64.1 & $60.1,68.0$ \\
\hline Island health & 79 & 8.6 & 7.9 & $5.8,10.0$ \\
\hline Northern health & 20 & 2.2 & 1.4 & $0.6,2.1$ \\
\hline Unknown & 20 & - & - & - \\
\hline \multicolumn{5}{|l|}{ Socioeconomic confounders } \\
\hline \multicolumn{5}{|l|}{ Education } \\
\hline Some high school or less & 382 & 40.9 & 26.0 & $23.0,29.1$ \\
\hline Completed high school & 553 & 59.1 & 74.0 & $70.9,77.0$ \\
\hline Unknown & 1 & - & - & - \\
\hline \multicolumn{5}{|l|}{ Employed } \\
\hline No & 722 & 77.1 & 65.6 & $61.6,69.7$ \\
\hline Yes & 214 & 22.9 & 34.4 & $30.3,38.4$ \\
\hline \multicolumn{5}{|l|}{ Behavioral confounders } \\
\hline \multicolumn{5}{|l|}{ History of incarceration } \\
\hline No & 440 & 47.2 & 66.8 & $63.5,70.1$ \\
\hline Yes & 493 & 52.8 & 33.2 & $29.9,36.5$ \\
\hline Unknown & 3 & - & - & - \\
\hline
\end{tabular}


Table 1 (continued)

\begin{tabular}{|c|c|c|c|c|}
\hline Variable & $\mathrm{N}=936$ & Crude \% & Weighted $\%$ & $\begin{array}{l}95 \% \text { CI of } \\
\text { weighted } \\
\%\end{array}$ \\
\hline \multicolumn{5}{|l|}{ Current illicit drug use } \\
\hline No & 431 & 46.3 & 56.6 & $52.6,60.5$ \\
\hline Yes & 500 & 53.7 & 43.4 & $39.5,47.4$ \\
\hline Unknown & 5 & - & - & - \\
\hline \multicolumn{5}{|l|}{ History of IDU } \\
\hline No & 356 & 38.2 & 66.4 & $63.2,69.5$ \\
\hline Yes & 575 & 61.8 & 33.6 & $30.5,36.8$ \\
\hline Unknown & 5 & - & - & - \\
\hline \multicolumn{5}{|l|}{ Current alcohol problem } \\
\hline No & 448 & 48.4 & 58.2 & $54.3,62.1$ \\
\hline Yes & 478 & 51.6 & 41.8 & $37.9,45.7$ \\
\hline Unknown & 10 & - & - & - \\
\hline \multicolumn{5}{|l|}{ Recent violence } \\
\hline No & 789 & 84.8 & 89.7 & $87.7,91.8$ \\
\hline Yes & 141 & 15.2 & 10.3 & $8.2,12.3$ \\
\hline Unknown & 6 & - & - & - \\
\hline \multicolumn{5}{|l|}{ I have been able to accept the fact that I have HIV } \\
\hline Strongly agree & 350 & 37.5 & 42.5 & $38.5,46.6$ \\
\hline Agree & 488 & 52.2 & 48.4 & $44.4,52.4$ \\
\hline Neutral & 42 & 4.5 & 4.1 & $2.6,5.6$ \\
\hline Disagree & 43 & 4.6 & 4.1 & $2.6,5.6$ \\
\hline Strongly disagree & 11 & 1.2 & 0.9 & $0.2,1.5$ \\
\hline Unknown & 2 & - & - & - \\
\hline Perceived neighborhood cohesion (per 1-unit increase) median (Q1-Q3) & 929 & $56(41-47)$ & $60.3(44.4-71.4)$ & - \\
\hline \multicolumn{5}{|l|}{ Clinical confounders } \\
\hline \multicolumn{5}{|l|}{ Mental health disorder diagnosis } \\
\hline No & 338 & 36.2 & 42.4 & $38.4,46.5$ \\
\hline Yes & 595 & 63.8 & 57.6 & $53.5,61.6$ \\
\hline Unknown & 3 & - & - & - \\
\hline \multicolumn{5}{|l|}{ Depressive symptoms } \\
\hline No & 397 & 42.6 & 49.9 & $45.9,53.9$ \\
\hline Yes & 534 & 57.4 & 50.1 & $46.1,54.1$ \\
\hline Unknown & 5 & - & - & - \\
\hline \multicolumn{5}{|l|}{ Adherence $\geq 95 \% 1$ year after first ART date } \\
\hline No & 448 & 49.0 & 38.5 & $34.7,42.3$ \\
\hline Yes & 466 & 51.0 & 61.5 & $57.7,65.3$ \\
\hline Unknown & 22 & - & - & - \\
\hline \multicolumn{5}{|l|}{ BMI } \\
\hline Underweight & 62 & 6.7 & 3.9 & $2.8,5.0$ \\
\hline Normal & 618 & 66.4 & 64.2 & $60.3,68.2$ \\
\hline Overweight & 186 & 20.0 & 23.9 & $20.3,27.5$ \\
\hline Obese & 65 & 7.0 & 7.9 & $5.7,10.2$ \\
\hline Unknown & 5 & - & - & - \\
\hline $\mathrm{CD} 4$ at interview date (per 100-unit increase) median (Q1-Q3) & 936 & $350(220-530)$ & $410(270-600)$ & - \\
\hline
\end{tabular}

Percentages obtained through weighting with inverse probability of participation weighting (IPPW) presented here, along with the $95 \%$ confidence intervals of the weighted percentages

$I D U$ injection drug use, $A R T$ antiretroviral therapy, BMI Body Mass Index, Q1-Q3 Quartile 1-Quartile 3

${ }^{a}$ Includes individuals who identified as Asian, African, Caribbean, Black, Central American, Middle Eastern, South American, and other 
Table 2 Reported cause of death among individuals who died (overall) and for the identified social isolation classes: (1) socially connected, (2) minimally isolated and (3) socially isolated $(\mathrm{N}=229)$

\begin{tabular}{lllll}
\hline Cause of death & Overall & Socially connected & Minimally isolated & Socially isolated \\
$\mathrm{N}=229(\%)$ & $\mathrm{N}=68(\%)$ & $<6(\%)$ & $<$ & $0(0.0)$ \\
\hline Accident or suicide & $5(2.2)$ & $<5$ & $52(38.2)$ & $13(52.0)$ \\
Chronic disease or co-morbidities & $94(41.0)$ & $29(42.6)$ & $49(36.0)$ & $7(28.0)$ \\
Drug and/or alcohol-related & $76(33.2)$ & $20(29.4)$ & $23(16.9)$ & $5(20.0)$ \\
HIV-related & $41(17.9)$ & $13(19.1)$ & $8(5.9)$ & $0(0.0)$ \\
Unknown $^{\text {a }}$ & $13(5.7)$ & $5(7.4)$ & & \\
\hline
\end{tabular}

ICD-10 codes related to each cause of death category are available in appendix (Online Appendix 1)

${ }^{a}$ Refers to unknown cause of death

Table 3 Chi-squared analyses of cause of death among individuals within identified social isolation classes $(\mathrm{N}=229)$

\begin{tabular}{|c|c|c|c|c|}
\hline \multirow[t]{2}{*}{ Cause of death } & \multicolumn{4}{|l|}{ Latent isolation class } \\
\hline & $\begin{array}{l}\text { Socially connected } \\
\mathrm{N}=68(\%)\end{array}$ & $\begin{array}{l}\text { Minimally isolated } \\
\mathrm{N}=136(\%)\end{array}$ & $\begin{array}{l}\text { Socially isolated } \\
\mathrm{N}=25(\%)\end{array}$ & P-value \\
\hline Accident or suicide & & & & 0.999 \\
\hline No & $62(98.4)$ & $124(96.9)$ & $25(100.0)$ & \\
\hline Yes & $<5$ & $<5$ & $0(0.0)$ & \\
\hline Chronic disease or co-morbidities & & & & 0.514 \\
\hline No & $34(54.0)$ & $76(59.4)$ & $12(48.0)$ & \\
\hline Yes & $29(46.0)$ & $52(40.6)$ & $13(52.0)$ & \\
\hline Drug and/or alcohol related & & & & 0.489 \\
\hline No & $43(68.3)$ & $79(61.7)$ & $18(72.0)$ & \\
\hline Yes & $20(31.7)$ & $49(38.3)$ & $7(28.0)$ & \\
\hline HIV-related & & & & 0.898 \\
\hline No & $50(79.4)$ & $105(82.0)$ & $20(80.0)$ & \\
\hline Yes & $13(20.6)$ & $23(18.0)$ & $5(20.0)$ & \\
\hline Unknown $^{\mathrm{a}}$ & $5(100.0)$ & $8(100.0)$ & $0(100.0)$ & - \\
\hline
\end{tabular}

ICD-10 codes related to each cause of death category are available in appendix (Online Appendix 1)

${ }^{\text {a }}$ Refers to unknown cause of death to be significantly associated with all-cause mortality, the direction of the effect was as anticipated (aOR: 1.07, 95\% CI 0.89, 1.29).

Additional sensitivity analyses were carried out to further examine the effect of social isolation on all-cause mortality. In one analysis, we removed CD4 cell count as a confounder from the multivariable model (Table IIS); we observed a decrease in effect size ([MI] aOR: 1.04, 95\% CI 0.87, 1.26; [SI] aOR: $1.40,95 \%$ CI 1.03, 1.90). Further, we also excluded history of injection drug use from the multivariable model, where we observed a similarly small increase in effect size ([MI] aOR: 1.13, 95\% CI 0.94, 1.36; [SI] aOR: $1.55,95 \%$ CI 1.14, 2.10) (Table IIIS). In the last sensitivity analysis, we removed any marker of mental health (a mental health diagnosis ever, depressive symptoms and HIV acceptance) from the adjusted model (Table IVS). We noted a small decrease in effect size ([MI] aOR: $1.06,95 \%$ CI 0.88 , 1.28; [SI] aOR: $1.43,95 \%$ CI 1.05, 1.93).

\section{Discussion}

Our analysis identified three classes of social isolation among PLHIV in our sample: Socially Connected, Minimally Isolated, and Socially Isolated. We then investigated the relationship between isolation and all-cause mortality. While the relationship between the MI group and allcause mortality was non-significant, we found a significant association between the SI group and all-cause mortality, after adjustment for confounders. Descriptively, the leading cause of death, overall, was chronic disease or co-morbidities and the second leading cause of death was drug and/or alcohol-related harms.

With advancements in effectiveness and uptake of ART, PLHIV are living longer lives [47]. However, challenges remain that elevate the risk of adverse health outcomes among PLHIV. This is highlighted by the differences in 
Table 4 Multivariable logistic regression model, weighted by inverse probability of participation weights, quantifying the association between identified social isolation classes: (1) socially connected, (2) minimally isolated and (3) socially isolated, and all-cause mortality $(\mathrm{N}=870)$

\begin{tabular}{|c|c|}
\hline \multirow[t]{2}{*}{ Variable } & $\begin{array}{l}\text { Death before December 31st, } 2017 \\
\text { (no vs. yes) }\end{array}$ \\
\hline & Adjusted odds ratio $(95 \% \mathrm{CI})$ \\
\hline \multicolumn{2}{|l|}{ Exposure } \\
\hline \multicolumn{2}{|l|}{ Social isolation } \\
\hline Socially connected & 1.00 \\
\hline Minimally isolated & $1.07(0.89,1.29)$ \\
\hline Socially isolated & $1.48(1.08,2.01)$ \\
\hline \multicolumn{2}{|l|}{ Sociodemographic confounders } \\
\hline Age (per 1-unit increase) & $1.04(1.03,1.05)$ \\
\hline Stable housing & $0.52(0.43,0.65)$ \\
\hline \multicolumn{2}{|l|}{ Regional health authority } \\
\hline Interior health & 1.00 \\
\hline Fraser health & $2.48(1.46,4.21)$ \\
\hline Vancouver coastal health & $1.70(1.02,2.83)$ \\
\hline Island health & $1.64(0.91,2.93)$ \\
\hline Northern health & $2.62(1.12,6.11)$ \\
\hline \multicolumn{2}{|l|}{ Socioeconomic confounders } \\
\hline Employed & $0.39(0.31,0.49)$ \\
\hline \multicolumn{2}{|l|}{ Behavioral confounders } \\
\hline \multicolumn{2}{|l|}{ I have been able to accept the fact that I have HIV } \\
\hline Strongly agree & 1.00 \\
\hline Agree & $1.08(0.90,1.29)$ \\
\hline Neutral & $1.52(1.02,2.28)$ \\
\hline Disagree & $1.44(0.94,2.18)$ \\
\hline Strongly disagree & $0.79(0.33,1.88)$ \\
\hline History of incarceration & $1.61(1.30,1.98)$ \\
\hline History of IDU & $1.77(1.41,2.22)$ \\
\hline Perceived neighbourhood cohesion (per 1-unit increase) & $1.02(1.01,1.02)$ \\
\hline \multicolumn{2}{|l|}{ Clinical confounders } \\
\hline Mental health disorder diagnosis & $0.66(0.55,0.79)$ \\
\hline Depressive symptoms & $1.42(1.17,1.71)$ \\
\hline \multicolumn{2}{|l|}{ BMI } \\
\hline Underweight & 1.00 \\
\hline Normal & $0.46(0.32,0.68)$ \\
\hline Overweight & $0.28(0.18,0.43)$ \\
\hline Obese & $0.36(0.22,0.59)$ \\
\hline CD4 at interview date (per 100-unit increase) & $0.90(0.86,0.93)$ \\
\hline
\end{tabular}

The model did not include participants with unknown (missing) information for confounders, resulting in a final sample size of 870 when running the multivariable logistic regression model

$a O R$ adjusted odds ratio, $C I$ confidence interval, $I D U$ injection drug use, $B M I$ body mass index all-cause mortality rates in our sample of PLHIV (30.3 per $1000 \mathrm{PYs} ; 95 \%$ CI 22.2, 38.3), in comparison to that of the general Canadian population in 2016 (7.4 per 1000 PYs) [37]. Given this stark difference, there is a need to better understand the impact of psychosocial factors, such as social isolation, on quality of life among PLHIV. As previously described, the leading cause of death within this sample is chronic disease and co-morbidities, inclusive of cardiovascular disease and pulmonary disease; social isolation has been associated with these conditions in the general population $[5,10,12]$. This is particularly relevant for PLHIV, who are at increased risk of co-morbidities, such as cardiovascular disease and non-AIDS related cancers, due to chronic inflammation as a consequence of immune activation and dysregulation [48-50]. Previous research also suggests that social isolation may elevate inflammation levels [51]. Therefore, we hypothesize that inflammation may act as a mediator along the pathway 
between social isolation and all-cause mortality [13]. This hypothetical mechanism is similar to that of the stressmediated pathway, wherein greater levels of stress result in heightened immune activation and inflammation [13, 14]. Therefore, it is possible that social isolation is acting synergistically with other immunological processes to elevate the degree of inflammation among PLHIV, leading to heightened risk of morbidity and mortality; this demonstrates the importance of focusing on the impacts of psychosocial determinants to improve quality of life among PLHIV.

While we did not investigate this in our analyses, we hypothesize that social isolation may be intrinsically associated with the second leading cause of death within this sample: drug and/or alcohol-related harms. Among PLHIV, rates of both alcohol use and substance use disorders are higher than in the general population [52-54]. This is particularly relevant in the context of the overdose crisis occurring throughout North America, largely a result of synthetic opioids, such as fentanyl and other analogues [55]. Overdose deaths within BC have increased dramatically in recent years, jumping from 211 in 2010 to 1535 deaths in 2018 [55]. These fatal overdoses have resulted in a decrease in the overall life expectancy within the province $[55,56]$ and the declaration of a public health emergency [57]. Throughout the province, approximately $70 \%$ of overdose events that resulted in death involved people who were consuming substances alone [56]. Therefore, it is conceivable that socially isolated individuals are more vulnerable to fatal overdose events, given that they may be more likely to use alone. As such, while we focused our modeling on all-cause mortality (grouping all causes of death), we hypothesize that there may be two avenues leading to death among people who are socially isolated; one being the physiological mechanism as a result of inflammatory responses, and the other involving harms related to substance use.

These pathways are potentially reflected in the all-cause mortality rates observed per isolation class, wherein both the age-standardized all-cause mortality rates and rate ratios increase with heightened isolation. The greatest mortality rate is observed among the SI class, which further emphasizes the potential vulnerability faced by socially isolated individuals. While it should be noted that the chi-squared analyses resulted in no significant differences between social isolation classes per cause of death, it is feasible that this is a result of small cell sizes. Lastly, given the stepwise nature of the effects of social isolation observed in our data (as the effect size for the MI class is smaller than that for the SI class), it could be hypothesized that the negative impacts of isolation are not an all-or-none phenomenon; rather, social isolation could be working in a more gradual, insidious manner to impact health outcomes.
Positive actions to mitigate social isolation can be approached broadly from a public policy standpoint [11]; experts in the field have called for inquiries into social isolation at post-surgical clinical follow-up $[58,59]$ and during routine geriatric assessments [59] within the larger community. As such, HIV physicians and other healthcare practitioners providing care to PLHIV could consider including similar isolation inquiries into their regular practices, and refer patients to community-based organizations for opportunities related to social engagement. This is of particular importance and interest to practitioners due to the noted relationship between social support and HIV-related quality of life [60]. Social support can protect against the negative effects of stigma on HIV-related health outcomes [61]. However, stigma is also associated with lower levels of social support [19], meaning that identifying individuals with lower social support as a result of stigma or other factors is an important consideration when evaluating health outcomes, due to the protective effects of social support. Further to this point, individuals who are isolated, by definition, participate less in their communities. That being said, people who are experiencing loneliness are more likely to seek medical care and it has been hypothesized that this may be done, in part, as a means of fulfilling social needs [62]. In this scenario, there may be a unique opportunity to engage with PLHIV experiencing social isolation.

Our analysis has certain limitations to consider. First, our use of observational data makes it difficult to establish causality due to unmeasured or imperfectly measured confounders. Further, while we hypothesize that social isolation results in morbidities and subsequent mortality as a result of inflammation and behavioral-based mechanisms, we did not examine this explicitly in our study. It is possible that the pathway is bi-directional, meaning that illness precludes social participation thus resulting in isolation. An additional consideration involves the instability of social isolation and potential fluctuations in isolation over time [63]; we used cross-sectional measures related to social isolation in our LCA that were collected at the time of the LISA interview (2007-2010). Therefore, the further away the mortality event is from the interview, the more difficult it is to temporally link social isolation to death later on in time. However, previous studies which have explored social isolation and health-related outcomes did so with a follow-up period varying from 3 to 21 years [30]. Investigations into the impact of transient versus chronic loneliness on health status demonstrated that, although those who were chronically lonely experienced the most negative health outcomes, both loneliness states resulted in lower health status [64]. Longitudinal analyses investigating the effects of periodic versus chronic social isolation, and assessments of the proportion of overall life spent in isolation on mortality should be carried out. This 
study oversampled people marginalized by socio-structural inequities; however, potential bias as a result of selective participation was addressed through inverse probability of participation weighting. Lastly, in our examination of specific causes of death, small sample sizes may explain the lack of significant findings. Further investigation is warranted with larger sample sizes to investigate social isolation and mortality, by cause of death.

\section{Conclusions}

Our study indicates that social isolation is linked with allcause mortality among PLHIV in BC. In order to unpack this relationship, future research should include community consultation and qualitative analyses, with the intent to investigate positive actions that would result in greater integration of PLHIV into communities, averting experiences of isolation. Our work indicates that the examination of interventions that may mitigate social isolation is warranted. The importance of social relationships on health and well-being, along with other psychosocial factors that affect health outcomes, must be considered with gravity.

Acknowledgements This work was supported by the Canadian Institutes of Health Research (Grant 53396). We would like to sincerely thank all of the LISA participants who took the time to share their experiences with the study; the work presented here would not have been possible without their commitment, and we hope that we do justice to their stories. We would also like to acknowledge the LISA Community Advisory Committee: Terry Howard, Rosa Jamal, Isabella Kirchner, Sandy Lambert, Kecia Larkin, Steve Levine, Melissa Medjuck, Stacie Migwans, Sam Mohan, Lori Montgomery, Glynn Townson, Michelle Webb, and Sarah White. Lastly, we want to thank and acknowledge the study co-investigators: Dr. Rolando Barrios, Dr. David Burdge, Dr. Marianne Harris, Dr. David Henderson, Dr. Thomas Kerr, Dr. Julio S.G. Montaner, Dr. Thomas Patterson, Dr. Eric Roth, Dr. Mark W. Tyndall, Dr. Brian Willoughby and Dr. Evan Wood.

Author Contributions MEM: study conception, study design, data interpretation, writing, editing, final approval; TM: study design, data interpretation, editing, final approval; KGC: study design, data interpretation, editing, final approval; KC: study conception, data interpretation, editing, final approval; LW: statistical analysis, editing, final approval; JT: data analysis, editing, final approval; KS: study conception, editing, final approval; SP: study conception, editing, final approval; VDL: study design, editing, final approval; RSH: study conception, study design, data interpretation, editing, final approval.

\section{Compliance with Ethical Standards}

Conflict of interest The authors have no conflicts of interest to declare.

Ethical Approval Eligible participants provided written informed consent. Ethical approval for this study was obtained from research ethics boards at the University of British Columbia/Providence Health Care, Simon Fraser University, the University of Victoria and Vancouver Coastal Health (H16-00497).

\section{References}

1. Shankar A, McMunn A, Banks J, Steptoe A. Loneliness, social isolation, and behavioral and biological health indicators in older adults. Health Psychol. 2011;30(4):377-85.

2. Cornwell EY, Waite LJ. Social disconnectedness, perceived isolation and health among older adults. J Health Soc Behav. 2009;50(1):31-48.

3. de Jong GJ, van Tilburg J, Dykstra PA. Loneliness and social isolation. In: Vangelisti A, Perlman D, editors. The Cambridge handbook of personal relationships. Cambridge: Cambridge University Press; 2006. p. 485-500.

4. Perissinotto CM, Stijacic Cenzer I, Covinsky KE. Loneliness in older persons: a predictor of functional decline and death. Arch Intern Med. 2012;172(14):1078-83.

5. Holt-Lunstad J, Smith TB, Baker M, Harris T, Stephenson D. Loneliness and social isolation as risk factors for mortality: a meta-analytic review. Perspect Psychol Sci. 2015;10(2):227-37.

6. McPherson M, Smith-Lovin L, Brashears ME. Social isolation in America: changes in core discussion networks over two decades. Am Sociol Rev. 2006;71(3):353-75.

7. Kim DA, Benjamin EJ, Fowler JH, Christakis NA. Social connectedness is associated with fibrinogen level in a human social network. Proc Biol Sci. 1837;2016(283):20160958.

8. House JS, Landis KR, Umberson D. Social relationships and health. Science. 1988;241(4865):540-5.

9. Pantell M, Rehkopf D, Jutte D, Syme SL, Balmes J, Adler N. Social isolation: a predictor of mortality comparable to traditional clinical risk factors. Am J Public Health. 2013;103(11):2056-62.

10. Holt-Lunstad J, Smith TB, Layton JB. Social relationships and mortality risk: a meta-analytic review. PLoS Med. 2010;7(7):e1000316.

11. Umberson D, Montez JK. Social relationships and health: a flashpoint for health policy. J Health Soc Behav. 2010;51(suppl):54-66.

12. Leigh-Hunt N, Bagguley D, Bash K, Turner V, Turnbull S, Valtorta $\mathrm{N}$, et al. An overview of systematic reviews on the public health consequences of social isolation and loneliness. Public Health. 2017;152:157-71.

13. Yang YC, McClintock MK, Kozloski M, Li T. Social isolation and adult mortality: the role of chronic inflammation and sex differences. J Health Soc Behav. 2013;54(2):183-203.

14. Uchino BN. Social support and health: a review of physiological processes potentially underlying links to disease outcomes. J Behav Med. 2006;29(4):377-87.

15. Everson-Rose SA, Lewis TT. Psychosocial factors and cardiovascular diseases. Annu Rev Public Health. 2005;26:469-500.

16. Knox SS, Uvnäs-Moberg K. Social isolation and cardiovascular disease: an atherosclerotic pathway? Psychoneuroendocrinology. 1998;23(8):877-90.

17. Brummett BH, Barefoot JC, Siegler IC, Clapp-Channing NE, Lytle BL, Bosworth HB, et al. Characteristics of socially isolated patients with coronary artery disease who are at elevated risk for mortality. Psychosom Med. 2001;63:267-72.

18. Steptoe A, Shankar A, Demakakos P, Wardle J. Social isolation, loneliness, and all-cause mortality in older men and women. PNAS. 2013;110(15):5797-801.

19. Rueda S, Mitra S, Chen S, Gogolishvili D, Globerman J, Chambers L, et al. Examining the associations between HIV-related stigma and health outcomes in people living with HIV/AIDS: a series of meta-analyses. BMJ Open. 2016;6(7):e011453.

20. Bloch M. Frailty in people living with HIV. AIDS Res Ther. 2018;15(1):19-23.

21. Greene M, Covinsky KE, Valcour V, Miao Y, Madamba J, Lampiris $\mathrm{H}$, et al. Geriatric syndromes in older HIV-infected adults. J Acquir Immune Defic Syndr. 2015;69(2):161-7. 
22. Siemon JS, Blenkhorn L, Wilkins S, O'Brien KK, Solomon PE. A grounded theory of social participation among older women living with HIV. Can J Occup Ther. 2013;80(4):241-50.

23. McIntosh RC, Rosselli M. Stress and coping in women living with HIV: a meta-analytic review. AIDS Behav. 2012;16(8):2144-59.

24. Emlet CA. A comparison of HIV stigma and disclosure patterns between older and younger adults living with HIV/AIDS. AIDS Patient Care STDs. 2006;20(5):350-8.

25. Shippy RA, Karpiak SE. The aging HIV/AIDS population: fragile social networks. Aging Ment Health. 2005;9(3):246-54.

26. Duncan KC, Salters K, Forrest JI, Palmer AK, Wang H, O’Brien $\mathrm{N}$, et al. Cohort profile: longitudinal investigations into supportive and ancillary health services. Int J Epidemiol. 2013;42(4):947-55.

27. Hogg RS, Heath K, Yip B, Craib KJP, O'Shaughnessy MV, Schechter MT, et al. Improved survival among HIV-infected individuals following initiation of antiretroviral therapy. JAMA. 1998;279(6):450-4.

28. Hogg RS, Yip B, Chan KJ, Wood E, Craib KJP, O'Shaughnessy $\mathrm{MV}$, et al. Rates of disease progression by baseline CD4 cell count and viral load after initiating triple-drug therapy. JAMA. 2001;286(20):2568-77.

29. Patterson S, Cescon A, Samji H, Cui Z, Yip B, Lepik KJ, et al. Cohort profile: HAART Observational Medical Evaluation and Research (HOMER) cohort. Int J Epidemiol. 2015;44(1):58-67.

30. Valtorta NK, Kanaan M, Gilbody S, Ronzi S, Hanratty B. Loneliness and social isolation as risk factors for coronary heart disease and stroke: systematic review and meta-analysis of longitudinal observational studies. Heart. 2016;102(13):1009-166.

31. Rosengren A, Wilhelmsen L, Orth-Gomer K. Coronary disease in relation to social support and social class in Swedish men. A 15 year follow-up in the study of men born in 1933. Eur Heart J. 2004;25(1):56-63.

32. Lanza ST, Collins LM, Lemmon DR, Schafer JL. PROC LCA: a SAS procedure for latent class analysis. Struct Equ Model. 2007;14(4):671-94.

33. Lanza ST, Rhoades BL. Latent class analysis: an alternative perspective on subgroup analysis in prevention and treatment. Prev Sci. 2013;14(2):157-68.

34. Marziali ME, Card KG, McLinden T, Closson K, Wang L, Trigg J, Salters K, Lima VD, Parashar S, Hogg RS. Correlates of social isolation among people living with HIV in British Columbia. Canada. AIDS Care. 2020. https://doi.org/10.1080/09540 121.2020.1757607.

35. Hawkins RL, Abrams C. Disappearing acts: the social networks of formerly homeless individuals with co-occurring disorders. Soc Sci Med. 2007;65(10):2031-42.

36. Thompson SJ, Pollio DE, Eyrich K, Bradbury E, North CS. Successfully exiting homelessness: experiences of formerly homeless mentally ill individuals. Eval Program Plann. 2004;27(4):423-31.

37. Table 13-10-0710-01: deaths and mortality rates, by age group [database online] [Internet]. 2019. https://www150.statc an.gc.ca/t1/tbl1/en/tv.action?pid=1310071001\& pickMember $\mathrm{s} \% 5 \mathrm{~B} 0 \% 5 \mathrm{D}=1.11 \&$ pickMembers $\% 5 \mathrm{~B} 1 \% 5 \mathrm{D}=3.1$. Accessed 10 July 2019.

38. Buckner JC. The development of an instrument to measure neighborhood cohesion. Am J Community Psychol. 1988;16(6):771-91.

39. Government of British Columbia. Health authorities [Internet]. https://www2.gov.bc.ca/gov/content/health/about-bc-s-healt h-care-system/partners/health-authorities. Accessed 10 July 2019.

40. Ewing JA. Detecting alcoholism: the CAGE questionnaire. JAMA. 1984;252(14):1905-7.

41. Zhang W, O'Brien N, Forrest JI, Salters KA, Patterson TL, Montaner JSG, et al. Validating a shortened depression scale (10 item CES-D) among HIV-positive people in British Columbia, Canada. PLoS ONE. 2012;7(7):e40793.
42. Weir CB, Jan A. BMI classification percentile and cut off points. Treasure Island (FL): StatPearls Publishing; 2019.

43. Wood E, Montaner JSG, Yip B, Tyndall MW, Schechter MT, O'Shaughnessy MV, et al. Adherence and plasma HIV RNA responses to highly active antiretroviral therapy among HIV-1 infected injection drug users. CMAJ. 2003;169(7):656-61.

44. Card KG, Lachowsky NJ, Cui Z, Carter A, Armstrong H, Shurgold $\mathrm{S}$, et al. A latent class analysis of seroadaptation among gay and bisexual men. Arch Sex Behav. 2018;47(1):95-106.

45. Bonander C, Nilsson A, Bjork J, Bergstrom GML, Stromberg U. Participation weighting based on sociodemographic register data improved external validity in a population-based cohort study. J Clin Epidemiol. 2018;108:54-63.

46. Lima VD, Geller J, Bangsberg DR, Patterson TL, Daniel M, Kerr T, et al. The effect of adherence on the association between depressive symptoms and mortality among HIV-infected individuals first initiating HAART. AIDS. 2007;21:1175-83.

47. Samji H, Cescon A, Hogg RS, Modur SP, Althoff KN, Buchacz K, et al. Closing the gap: increases in life expectancy among treated HIV-positive individuals in the United States and Canada. PLoS ONE. 2013;8(12):e81355.

48. Seyler L, Lacor P, Allard SD. Current challenges in the treatment of HIV. Pol Arch Intern Med. 2018;128(10):609-16.

49. Deeks SG, Lewin SR, Havlir DV. The end of AIDS: HIV infection as a chronic disease. Lancet. 2013;382(9903):1525-33.

50. Deeks SG. HIV infection, inflammation, immunosenescence, and aging. Annu Rev Med. 2011;62:141-55.

51. Kiecolt-Glaser JK, Gouin JP, Hantsoo L. Close relationships, inflammation, and health. Neurosci Biobehav Rev. 2010;35(1):33-8.

52. Bing EG, Burnam A, Longshore D, Fleishman JA, Sherbourne $\mathrm{CD}$, London AS, et al. Psychiatric disorders and drug use among human immunodeficiency virus-infected adults in the United States. Arch Gen Psychiatry. 2001;58(8):721-8.

53. Galvan F, Bing EG, Fleishman JA, London AS, Caetano R, Burnam $\mathrm{M}$, et al. The prevalence of alcohol consumption and heavy drinking among people with HIV in the United States: results from the HIV Cost and Services Utilization Study. J Stud Alcohol. 2002;63(2):179-86

54. Rabkin J, McElhiney M, Ferrando S. Mood and substance use disorders in older adults with HIV/AIDS: methodological issues and preliminary evidence. AIDS. 2004;18(suppl 1):43-8.

55. Ministry of Public Safety and Solicitor General. Illicit drug overdose deaths in BC: January 1, 2009 to March 31, 2019. Published May 15, 2019.

56. Ministry of Public Safety and Solicitor General. Illicit drug overdose deaths in BC: findings of coroners' investigations. Published September 27, 2018.

57. Office of the Provincial Health Officer. Stopping the harm: decriminalization of people who use drugs in BC. Published 2019.

58. Manemann SM, Chamberlain AM, Roger VL, Griffin JM, Boyd CM, Cudjoe TKM, et al. Perceived social isolation and outcomes in patients with heart failure. J Am Heart Assoc. 2018;7(11):e008069.

59. Patel RS, Wardle K, Parikh RJ. Loneliness: the present and the future. Age Ageing. 2019;48(4):476-7.

60. Bekele T, Rourke SB, Tucker R, Greene S, Sobota M, Koornstra $\mathrm{J}$, et al. Direct and indirect effects of perceived social support on health-related quality of life in persons living with HIV/AIDS. AIDS Care. 2013;25(3):337-46.

61. Earnshaw VA, Lang SM, Lippitt M, Jin H, Chaudoir SR. HIV stigma and physical health symptoms: do social support, adaptive coping, and/or identity centrality act as resilience resources? AIDS Behav. 2015;19(1):41-9. 
62. Gerst-Emerson K, Jayawardhana J. Loneliness as a public health issue: the impact of loneliness on health care utilization among older adults. Am J Public Health. 2015;105(5):1013-9.

63. Wenger G, Burholt V. Changes in levels of social isolation and loneliness among older people in a rural area: a twenty-year longitudinal study. Can J Aging. 2004;23(2):115-27.

64. Martín-María N, Caballero FF, Miret M, Tyrovolas S, Haro JM, Ayuso-Mateos JL, et al. Differential impact of transient and chronic loneliness on health status: a longitudinal study. Psychol Health. 2019. https://doi.org/10.1080/08870446.2019.1632312.

Publisher's Note Springer Nature remains neutral with regard to jurisdictional claims in published maps and institutional affiliations. 